\title{
Memória e Identidade Social
}

Ana Lucia Silva Enne"

\section{RESUMO}

Nas sociedades da escrita, histórias de vida recontadas através de biografias nascidas na tradição oral, continuaram a servir como modelo para a produção cultural. Hoje, as tecnologias digitais potencializam o espaço da biografia na cultura contemporânea. Este artigo busca refletir sobre as novas tecnologias de comunicação, a escrita e a biografia como extensões da memória e instrumentos de transmissão de saber.

\section{ABSTRACT}

In the writing societies, histories of life retold by the way of the biographies born in the oral tradition, still functions as a model for the cultural production. Today, the digital technologies gin'e a new potencial to the space occupied by the biography in the comemporary culture. This article tries to make a reflection about the new communication technologies. the writing and the biography as extensions of memory and instrumcints of knowledge transmission.

\footnotetext{
:Jornalista formada pela PUC/RJ, Mestre e Doutoranda em Antropologia Social pelo PPGAS/Museu Nacional/UFRJ e professora dos cursos de Comunicação Social da UNIVERSO (Universidade Salgado de Oliveira) e da UCB (Universidade Castelo Branco).
} 
Em recente pronunciamento', Andreas Huyssen afirmou que o século XX foi marcado por um "boom da memória" como preocupação das ciências sociais e dos homens de um modo geral. Segundo ele, os cem últimos anos assistiram a uma intensa criação de "mercados da memória", que passam pela museificação, pela comercialização do passado via mídia, pela tentativa de reciclar o tempo no impulso em direção à memorialização, entre outras iniciativas de se recuperar "o aroma e o sabor" de que falava Proust ao se referir ao passado. A obsessão pelo passado seria própria desta cultura contemporânea ocidental, que vê, assustada, o presente desaparecer na compressão das coordenadas tradicionais de tempo e espaço. Na mesma ocasião ${ }^{2}$, Renato Ortiz declarou, também a respeito do século XX, que este seria o "século das descobertas dos tempos", citando exatamente a obra de Proust como um sinal claro deste processo.

Muitos outros pensadores têm apontado para esta valorização da memória e da tentativa de pensar as diversas categorias temporais como uma via de extrema riqueza nas análises das ciências sociais e no mapeamento da construção das identidades sociais. Este trabalho pretende, exatamente, recuperar algumas destas análises e apontamentos, de extrema importância para o meu projeto de tese, que versa sobre a construção de identidades na Baixada Fluminense. A evocação e a disputa por uma memória coletiva pelos diversos agentes sociais, inclusive pelos jornais impressos, configura-se em uma entrada decisiva para a tese. Neste sentido, tal trabalho agora apresentado é uma reflexão inicial sobre como as ciências sociais, em especial a Antropologia, a História e a Comunicação Social, têm se posicionado acerca desta problemática.

As pessoas que residem na Baixada Fluminense experimentam, continuamente, situações de conflito quanto às imagens que são projetadas para a região em que vivem, seja pelas representações da mídia e do senso comum, seja por aquelas criadas por setores da própria região. Esta relação de conflito evidencia-se ainda mais nas situações de contato, que, como indica Goffman ${ }^{3}$, aumentam as possibilidades de identificação negativa dos estigmatizáveis, caso típico dos moradores da Baixada. É no mundo fora da Baixada, na imprensa, na grande mídia, no emprego, no local em que se estuda, no fim de semana na praia, enfim, nas diversas situações de interação e estabelecimento de fronteiras é que esta possibilidade de receber sobre si a marca da discriminação e do preconceito, conjugadas nas visões estereotipadas de que a Baixada é um lugar que se resume à violência e pobreza, aparece com mais força. A 
experiência cotidiana de quem reside na Baixada é, portanto, não linear e composta de um imaginário (entendido aqui como un conjunto de imagens projetadas sobre determinado objeto. fruto de construções de matizes diversas e espelho/reflexo de discursos vários sobre o mesmo $)^{4}$ em permanente atualização.

F. Barth é referência fundamental para pensarmos como a construção de identidades está estritamente ligada à constituição de fronteiras móveis, cuja determinação de limites é de tal fluidez que termina por contaminar a própria constituição da identidade de um grupo ou de um segmento. ${ }^{5}$ Neste sentido, pensar de que maneira os moradores da Baixada Fluminense, através de seus diversos agentes e agências sociais, e os poderes públicos que estão em permanente interação com esses agentes, forjam as imagens de identidade coletiva. só é possível quando percebemos que estamos lidando com: a) uma representação de Baixada Fluminense multifacetada, que compreende diversos significados e sentidos. Para cada um deles, e de acordo com situações diversas, irá se estabelecer um tipo específico de interação que resultará em concepções distintas de identidade; b) um discurso polifônico. multivocal por excelência, que. embora empenhado em construir uma identidade positiva para o que se entende por Baixada Fluminense, é constituído de versões múltiplas, apropriações por vezes contraditórias, outras similares. ainda outras complementares, das diversas matérias-primas que embasam tais discursos, entre estas as categorias de tempo. espaço, memória e identidade: c) finalmente, que tanto os discursos externos (construídos via mídia ou através de um senso comum de pessoas que não residem na Baixada) quanto os internos (legitimados pelos diversos agentes e agências sociais da região) são conflitantes porém não excludentes, são partes de um mesmo processo. que a eles dá forma e conteúdo. Ou seja. tais discursos se constituem em práticas cotidianas não cristalizadas. em constante atualização. a partir das interações e das ações sociais que são vivenciadas pelos atores nas relações sociais, como já dito acima.

Maurice Halbwachs contribuiu definitivamente com as ciências sociais ao propor o conceito de memória coletiva e ao definir os quadros sociais que compõem esta memória. Para o autor, não existe memória puramente individual, posto que todo indivíduo está interagindo e sofrendo a ação da sociedade, através de suas diversas agências e instituições sociais. A forte influência de E. Durkheim pode ser sentida na concepção da memória coletiva como aquela que é referendada pelo(s) grupo(s) com o qual se convive e do qual extraímos nossas lembranças. É preciso não esquecer que a lembrança. ao contrário 
das referências históricas, pertence e está no indivíduo, mas isso não a torna única e individual. Mesmo a lembrança aparentemente mais particular possui um caráter particularista, remetendo a um grupo, a um contexto de interação. Assim, Halbwachs empreende uma dupla apropriação: de um lado, utiliza a noção tão cara em Durkheim de que os fatos sociais (e a memória seria um deles) ao mesmo tempo que podem ser encontrados na consciência individual, dela independem e se originam de uma consciência coletiva, que ao estar em todos não está em lugar nenhum, portanto ao estudar a parte estuda-se também o todo; de outro, percebe que na interação e no significado comum que a lembrança tem para o grupo é que se forma a memória coletiva, em uma referência direta aos preceitos weberianos. Como Ecléia Bosi demonstra, as colocações de Halbwachs são uma contraposição à visão de Bergson acerca da memória, onde esta é concebida como pertencente à esfera individual, em uma abordagem mais psicologizante. ${ }^{6}$

Para Halbwachs, uma questão fundamental acerca da memória coletiva, enquanto fato social, seria a sua ancoragem para cada indivíduo. Em que liames se apoiam os homens no presente para recuperarem o caminho de volta para o passado? Que elos se alojam entre passado e presente para que deles possamos ativar o que chamamos de memória? Novamente, voltamos ao "aroma" e ao "sabor" de que fala Proust, pistas, pegadas, indícios... E não só liames e elos entre o passado e presente, mas entre as diversas concepções individuais acerca do passado. Para se ter uma memória coletiva, é preciso interligar as diversas memórias dos indivíduos que fazem parte do grupo identificado como proprietário daquela memória.

Acredito que a concepção de memória coletiva seja vital para este trabalho, pois estamos lidando neste estudo com um conjunto de representações do passado onde agentes diversos procuram, a partir de preocupações do presente, reconstruir sua história. Seria a memória coletiva uma memória histórica? Halbwachs diz que não, que estamos lidando com memórias distintas. Sua posição sobre a relação memória $\mathrm{X}$ história, em que a primeira seria o abrigo das tradições e o lócus próprio da diversidade e da apropriação dos grupos, enquanto a história seria um "quadro de acontecimentos", com possibilidades universais, coloca de pronto a necessidade de pensarmos a própria concepção de história. O que eu, pesquisadora, estou entendendo aqui como História? Quando apresento no projeto de tese um delinear histórico que serve-me como referência para pensar a apropriação que os grupos fazem do passado, não estarei também cristalizando como única e verdadeira uma das versões da história? Não estarei 
associando a história a uma passagem de tempo linear e marcada por eventos que marcam continuidades e descontinuidades em sua estrutura? Ou não seria a História também um constante construir de versões, no mesmo sentido que estamos pensando aqui a memória? Ou como sugerem Souza Lima e Vianna', não deveríamos tomar a História como um conjunto de representações dadas a partir de interações sociais, a partir da apreensão do caráter fragmentado e múltiplo dos diversos discursos históricos, entre os quais a memória coletiva? Apesar da distinção proposta por Halbwachs. em que ponto em meu trabalho a memória coletiva e a memória histórica se entremeiam e mesmo se sobrepõem? Se a memória pode ser pensada como uma apropriação do passado, pensada como uma fonte provedora de recursos para a construção de um futuro possível, então não deve ser pensada também como um embate de versões, em alguns pontos convergentes, em tantos outros conflitantes?

As reflexões de Arjun Appadurai em seu artigo "The past as a scarce resource" apontam algumas possibilidades de saída para as dúvidas indicadas acima. Segundo Appadurai, o passado deve ser pensado como a fonte para a construção, no presente, de uma memória que ancore identidades e, principalmente, um instrumento de poder. Mas o passado não pode ser visto como dotado de um estoque inesgotável, sujeito a qualquer apropriação. Ao contrário, existem limitações neste uso do passado como recurso, dadas exatamente pela História dos acontecimentos. Ele compreende que o passado fornece um universo de significados que são disputados conflitivamente, não existindo, portanto, uma harmonia de versões.

No presente, os grupos envolvidos nesta disputa pelo passado vão administrar estes significados, vão postular a condição de guardadores e organizadores desta memória, pois isto tem um forte peso político. Metodologicamente, Appadurai sugere que o pesquisador faça uso de quatro dimensões para perceber que toda apropriação do passado está calcada em alguns aspectos formais, que seriam: autoridade, continuidade, profundidade e interdependência. $\mathrm{O}$ que o autor pretende demonstrar é que o universo simbólico do passado não é um manancial inesgotável para a construção de versões de memória e história, ao contrário, é, como sugere o título do artigo, um "recurso escasso". Existem pontos de ancoragem que são fundamentais, que estão sedimentados pela própria historiografia, retomando aqui a idéia de quadro de acontecimentos. Não basta reler o passado conforme as pretensões do grupo em termos de presente, é preciso que haja vínculos entre esta pretensão e os vestígios materiais desse passado, 
para que tal versão se sustente. Neste sentido, é preciso ter havido uma História. Dentre os acontecimentos do passado, os grupos irão buscar os símbolos que emprestem mais sentidos às suas necessidades do presente, mas estes símbolos não são ilimitados.

Também J. Peel, analisando as concepções do passado no presente Ijesha, aponta para a relação dialética entre estes dois marcos temporais. Segundo o autor, metodologicamente o pesquisador deve se perguntar como os grupos sociais, no presente, apropriam-se do passado, mas, principalmente, devem atentar para o porquê esta apropriação. Que significados têm, no presente, determinadas concepções históricas, ou memórias coletivas? Peel também aponta, no decorrer de seu trabalho, a intrínseca relação entre as apropriações do passado e a construção de memórias com a posição política que os grupos querem ocupar dentro dos quadros sociais do presente. Guardar a memória é ser dotado de um conhecimento profundo, diferente do conhecimento superficial partilhado pelo homem comum. Conhecimentos sobre o passado conferem ao seu portador autoridade. Nesta busca de propriedade e autoridade sobre o tempo e sobre a própria sociedade Ijesha, é possível perceber como os agentes sociais conjugam concepções históricas de um tempo linear com outras de tempos cíclicos, onde, em uma estrutura, é possivel apreender eventos significativos e reescrever a História e

12 a memória a partir destes pontos. Peel empreende inclusive uma análise etimológica das palavras acionadas neste trabalho de rememoração para demonstrar como há um forte componente de restauração, a presença constante de um refazer. Na própria acepção linguística, a idéia de recuperar o passado evoca uma criação sobre ele. A presença de rupturas e continuidades na análise do passado pode ser percebida, portanto, como uma tentativa de, através de discursos construídos a partir de evocações distintas, oferecer uma versão memorial sobre o passado que atenda a demandas específicas do presente.

No caso específico das apropriações do passado pelos diversos agentes e agências sociais na Baixada Fluminense, acredito que podemos pensar de forma semelhante. Sem dúvida, estamos lidando com construções de uma memória evocativa deste passado a partir de posições políticas assumidas no presente. Porém, existe um "quadro formal" relativo aos acontecimentos no passado no qual estes agentes precisam, necessariamente, se apoiar para configurarem suas versões memorialísticas, seja de continuidade ou ruptura. Este quadro formal, me parece, é garantido por esta História da Baixada Fluminense, que compreende períodos de ascensão e decadência em termos eco- 
nômicos, políticos e sociais, conforme descrevi em meu projeto de tese.

Estas possibilidades de apropriação do passiddo pela via do presente apontam para uma questão ainda maior: a construção de futuros possíveis. Assim, é no presente que a construção do passiado é dispulada como recurso para a construção de um futuro que responda às aspirações deste presente. A memória do passades seria. então, a memória do futuro? Melhor dizendo: a construçiáo de memórias sociais como estratégias políticas não são uma maneira de tentar enviesar a História para um caminho mais "apropriado". segundo a visão de cada grupo"?

Neste sentido, parece pertinente pensar as estratégicas de armazenamento e esquecimento do palssado. A construção dos museus, centros de memória e institutos historicos como depositários de uma concepção e versão da memória são indiciativos deste movimento. O que se guarda e armazená é o que se quer lembrar. pois o não mais visto tende ao esquecimento. A cultura material que é condicionada nestes espaços de memória são. como venho dizendo desde o início deste trabalho, o "aroma e o sabor" do passiado que se quer preservar. Néstor Canclini aponta para esta necessidade de criar mitos e monumentos de preservação do passiado como marcos fundamentais de construção de identidades. Como já disse Pierre Nora. podemos perceber os muscus. institutos históricos. calsas de cultural monumentos, entre outros, como "lugares de memórial". cuja funçãa é exititmente manter ativo o pertencimento a determinado vínculo identificatiórios".

Novamente voltamos à questão da alutenticidade, já evocada por Appadurai. Não é possível ancorar as representações do passado sobre virtualidades, é preciso a marca dia alutenticidade para legitimar tais sentidos. Por isso al intensa preocupação em erọtuer e preservar os "Jugares de memória". Por isso também a necessidade de mapear constantemente o que se compreende por tempo e espaço. noçoes de extrema fluidez mas de vital importancia quando da articulação de identidades calcadas em memórias coletivas e pertencimento territorial. como no caso da Baixada Fluminense.

Há, portanto, como aponta M. Pollák. um trabalho constante de "enquadramento da memória". É preciso escolher o que vai ser lembrado e o que deve ser esquecido. Tilmbém Pollak reitera que "as preocupações do momento constituem um elemento de estruturaçãó da memória"." Como Halbwachs. Pollak insiste no aspecto de construção da memória, como uma estratégia de agentes e agêncials sociais para ancorar identidades, pois há. segundo o autor. uma "liģação 
fenomenólogica muito estreita entre a memória e o sentimento de identidade". ${ }^{10}$ Pollak aponta que, na construção da identidade, é preciso levar-se em conta três elementos essenciais: a unidade física (novamente remetemos à idéia de lugar, ou seja, à concepção espacial, fundamental para este trabalho); a continuidade dentro do tempo (não só no sentido físico, mas moral e psicológico, como frisa o autor); e, finalmente, "o sentimento de coerência, ou seja, de que os diferentes elementos que formam um indivíduo são efetivamente unificados"

No caso específico do meu objeto de estudo, podemos perceber que tanto a tendência a armazenar a memória via arquivo de fontes materiais (caso das casas de memória e institutos históricos) quanto a busca de enquadrar a memória através de narrativas orais por parte dos movimentos culturais, muitas vezes procurando diminuir a importância desses lugares de memória instituídos materialmente, são estratégias manejadas pelos agentes sociais. Como já indiquei acima, não são posturas estáticas e podem ser remanejadas de acordo com demandas e interações específicas, mas, de qualquer forma, pode-se perceber que há uma tendência entre os dois movimentos de apropriação do passado de privilegiarem uma ou outra tática de rememoração.

$\mathrm{Na}$ verdade, tanto uma quanto outra estão a serviço da construção de "comunidades imaginárias", no sentido proposto por Benedict Anderson $^{-12}$, ou ainda, da "construção simbólica da comunidade", 14 como postula A.P. Cohen ${ }^{13}$. Nas duas acepções, o caráter decisivo para a demarcação de um pertencimento comunitário está na apreensão simbólica dos múltiplos significados, construídos via discurso, para esta "comunidade". Mais do que uma área demarcada fisicamente ou uma herança histórica partilhada por determinado número de membros, a comunidade seria um "local" de intensa fluidez e fronteiras móveis, cuja construção se daria a partir das interações sociais e não a partir das concepções tradicionais de tempo e espaço. Lugar seria aqui, conforme apresentado por Asa Briggs ${ }^{14}$, algo estabelecido não como simples denominação espacial, no sentido de espaço físicogeográfico, mas como fruto da relação dialética entre as experiências objetivas e subjetivas de pertencimento. Da mesma forma, a comunidade também seria formada a partir das interações, e não dada a priori pelas condições objetivas da vida cotidiana. Nesta construção simbólica do que se entende por comunidade, a apropriação do passado é, segundo Cohen, um recurso fundamental. Tradições e rupturas são construídas a partir do presente, criando o aparato simbólico a ser codificado e decodificado pelos membros do grupo, como demonstram os trabalhos de B. Anderson e E. Hobsbawn. ${ }^{15}$

Se entendemos e partilhamos das visões acima de que o que se 
entende por comunidade e identidade são construções simbólicas, resultantes de interações e conflitos, e não realidades dadas e cristalizadas, o objeto de estudo para esta tese apresenta-se em sua riqueza de possibilidades: de quantas Baixadas e de que Baixadas estão falando todos? O que se insere nesta noção de matiz geográfica, mas que se desdobra em tantas outras, caracterizada como Baixada? Quantas imagens e fragmentos destas encontramos no que se convencionou chamar de Baixada Fluminense? E, mais recentemente, como podemos pensar a Baixada Fluminense em uma sociedade marcada por valores globais, entre cles a fluidez das fronteiras e das identidades? Se estamos falando de discursos construídos, como pensá-los dentro de uma sociedade marcada exatamente pelo apogeu da informação? E, finalmente, se estamos falando na utilização de memórias coletivas como ponto de ancoragem para identidades, torna-se vital pensar o tempo como conceito e como realidade vivida, principalmente com a fragmentação das noções clássicas de tempo e espaço.

O processo de Globalização vem sugerindo novas interpretações para a questão do tempo e do espaço, ambas categorias fundantes neste trabalho. As novas relações entre o local e o global parecem apontar para uma compressão das visões do tempo e do espaço, crjando outras concepções e oferecendo outras possibilidades de construção do futuro. Como pensar a memória local a partir de una sociedade globalizada? De que fala, por exemplo, o grupo Cidade Negra, de uma memória coletiva que remete ao local, à própria Baixada, ou ao global, uma memória coletiva que remete a outros movimentos e correntes transnacionais e transculturais'? Os agentes sociais que, segundo aponto, renegam a construção da imagem da Baixada Fluminense via imprensa e também não se identificam com a memória coletiva que constrói uma visão glamourizada do passado, estão marcando, pelo esquecimento. um novo mito memorialístico, onde a adesão da coletividade não se dá no local, no regional, mas no global, em todas as tradições de resistência e construção de uma memória de novas etnicidades? Estas são algumas das questões a serem exploradas.

Les Back, em seu trabalho sobre as novas etnicidades em Londres $^{16}$, aponta para este caráter de adesão da memória de grupos locais com diásporas transnacionais, uma remissão a um elo antes perdido e agora reencontrado com um grupo de origem. especialmente ancestrais, que podem ser revividos e mesmo transformados (via absorção e readaptação a partir dos traços locais, razão pela qual Les Back utiliza a noção de rizoma proposta por Gattari e Deleuze), mas, que no fundo, permitem a criação de uma memória original e global. 
Canclini aborda esta questão quando fala do multiculturalismo e da constituição de culturas híbridas ${ }^{17}$, que celebram a interpenetração das culturas locais com traços que lhes são exteriores, resultando em novas apropriações e novas formas culturais. A mesma idéia está contida em Ulf Hannerz ${ }^{18}$, que aposta na idéia de "fluxos culturais" como explicação para este movimento típico da nova ordem mundial, onde a flexibilização das fronteiras postula novas identidades e exige um reexame das noções de tempo e espaço, o que vem sendo feito, de maneiras diversas, pelos próprios agentes sociais. A partir destas postulações, que me parecem pertinentes, em que contexto devo pensar a construção destas memórias na Baixada Fluminense? Como um fenômeno local, a partir das referências dentro/fora, como apontei no início deste texto? Ou como um fenômeno contemporâneo que adquiriu formas específicas no contexto regional? Aqui, acredito que os textos sobre etnicidade, fluxos e hibridização, que irão ser explorados mais detalhadamente em outro trabalho, poderão enriquecer profundamente o debate.

Jean-Pierre Vernant procura demonstrar, em seu texto ${ }^{19}$, o quanto a memória, em seu sentido original entre os gregos, apontava para outras direções que não as que são concebidas no mundo contemporâneo. Pela memória, reconstruíamos nosso elo com o mundo, com nossa origem, e menos com uma temporalidade. A memória seria matéria menos de uma cronologia e mais de uma cosmogonia. Memória e esquecimento seriam fontes nas quais tanto homens quanto deuses haveriam de beber, sendo a segunda marcadamente uma entrada para o "inferno", para a não superação, e a primeira uma maneira de garantir o tempo cíclico, um caráter mítico em relação ao pertencimento ao mundo desde sempre. Não seria a memória coletiva, enquanto apropriação de um passado nem sempre historicamente linear, também, em muitos casos, uma aderência ao mundo, ao mito da criação, e menos a uma concepção histórica do tempo? Se lembramos para esquecer, como diz Pollak ${ }^{20}$, não estamos construindo, com a memória coletiva, um passado comum com outros grupos que não aquele ao qual estamos diretamente filiados? Huyssen, na conferência aqui já citada, afirmou que uma das categorias constituintes da humanidade seria exatamente a "perda de um passado melhor", uma "perda fantasmagórica gerada pela própria História". Para ele, a cultura da memória poderia indicar uma atualização contemporânea desta busca contínua por este passado mitificado, por esta cosmogonia.

A sociedade globalizada aparece como elemento compressor das dimensões tradicionais do tempo e do espaço. Assim, a apropriação deste passado via meios de comunicação de massa, um passado que 
esvai o presente e prepara condiçoes paral a projeção do futuro, parece ser um elemento interessante para pensar a ação dos agentes sociais que encontrei na Baixada reunidos $\mathrm{cm}$ institutos históricos e casas da memória. No limiar de uma cultura que comprime o tempo para resgatar o passado, o esquecimento. aponta Huyssen. é a transgressão final. Neste sentido, o esquecimento e a memória. indissociados em sua origem mítica. scgundo demonstrou Vermant, reaparecem na cultura contemporânea. Não scria este o jogo das versões conflitivas encontradas em uma primeira abordagem na Baixada? Um jogo interpretativo de resgate $c$ negação de um passado cristalizado. oficializado e referendado pclas imagens midiáticas? Outra entrada que me parece insinuante. Huyssen terminou sua conferência dizendo que a noção de que a memória do futuro seria aquela do cyberespaço é errônea e enganadora. pois. segundo ele, são as memórias reais, que estão vivas, que serão o futuro. Pois é esta memória, marcada pela mudança, pelo seu caráter público, pelo medo do esquecimento próprio à sua instabilidade, que constitui de fato a memória social.

Assim como o tempo estaria sendo comprimido no mundo globalizado, as noções relacionadas ao espaço também não escapariam desta compressão. Kevin Hetherington'21 propõe a substituição dos mapas cartográficos de inspiração cartesiana e cuclidiana por outros, múltiplos e fragmentados, onde a idéia de redes. fluxos e interações estejam todo tempo presente. A própria idéila de região deveria ser questionada, o que me parece vital também para este trabalho. Neste sentido, a imagem proposta é a do espaço em branco, marcado pela catástrofe e pela entropia, onde tudo adquire sentido a partir da interação, e não a partir de scntidos dados. As fronteiras antes postuladas são comprimidas, mas. para o autor, não cessam de existir fronteiras, elas são reatualizadas nos fluxos e interações.

Todas estas reflexões são preliminalres. Neste momento, é cedo para apresentar resultados fechados. mas são estes os tortuosos e instigantes caminhos que se oferecem para ser trilhados. Por estes primeiras abordagens, podemos perceber que as consideraçõos sobre memória e identidade social são cruciais para a tese que pretendo desenvolver, mas só poderão ser percorriclas com mais sentido e utilidade a partir da realização sistemática do trabalho de campo c com a conjugação de outros trabalhos que estão $\mathrm{cm}$ preparação. referentes aos discursos midiáticos como criadores de imaginários de forte influência sobre o senso comum, às discussões sobre etnicidades e identidades, aos movimentos sociais e sua articulação polítical e. finalmente, às reflexões sobre os conceitos de tempo c de espaço. 


\section{Notas}

1 Conferência "Passados presentes: Memória, Mídia, Amnésia", proferida no evento "A construção do tempo e os futuros possíveis", realizado na Universidade Candido Mendes/RJ, de 10 a 12 de maio de 1999.

2 Conferência "Tempo e sociedade globalizada", no evento já citado.

3 GOFFMAN (1988).

4 ORLANDI (1999).

5 BARTH (1969 e 1989).

6 BOSI (1987, pp.15-17).

7 LIMA e VIANNA (1996).

8 NORA (1984).

9 POLLAK (1992, p.204).

10 Idem, ibidem, p.204.

1811 Idem, ibidem, p.204.

12 ANDERSON (1983).

13 COHEN (1985). Ver também WEBER (1944) e SIMMEL (1955).

14 BRIGGS (1985).

15 HOBSBAWN (1984).

16 BACK (1996).

17 CANCLINI, op.cit.

18 HANNERZ (1992).

19 VERNANT (1973).

20 POLLAK (1989).

21 Conferência "Onde está o mundo? A presença e a ausência do Globo", no evento citado. 


\section{Bibliografia}

ANDERSON, Benedict. "Introduction". Imagined Commmmities. London, Verso, 1983.

APPADURAI, Arjun. "The past as a scarce resource". In: Man. 16 (2), 1982.

BACK, Les. New ethnicities and urban culture. Racisms and multiculture in young lives. New York, St. Martin's Press, 1996.

BARTH, Fredrik. "Introdution". In: Ethnic Groups and Boundaries: The social organization of cultural difference. F. Barth (editor). George Allen \& Unwin. London. 1969.

. "The analysis of culture in complex societies". Ethnos 54 (3/4): 120-142. 1989.

BOSI, Ecléa. Memória e sociedade. São Paulo, T.A. Queiroz: Editora da Universidade de São Paulo, 1987.

BRIGGS, Asa. The collected essays of Asa Briggs. Vol. I. Words, Numbers, Places, People. Great Britain, The Harvester Press Limited, 1985.

CANCLINI, Néstor. Culturas híbridess. São Paulo, Edusp. 1998.

COHEN, A. P. The symbolic construction of community. London, Tavistock, 1985.

CONFERÊNCIA internacional "A construção do tempo e os futuros possíveis", realizada de 10 a 12 de maio de 1999. na Universidade Candido Mendes, RJ.

CONNERTON, Paul. How societies remember. Cambridge University Press, 1989.

GOFFMAN, Erving. Estigma. Notas sobre a manipulação da identidade deteriorada. RJ, Guanabara, 1988.

HALBWACHS, Maurice. A memória coletiva. SP. Vértice, 1990.

HANNERZ, Ulf. Cultural Complexity. Columbia University Press. New York. 1992. 
HOBSBAWM, Eric. "Introdução: A Invenção das Tradições". In: HOBSBAWN, E. e RANGER, T. (org.). A Invenção das Tradições. Rio de Janeiro, Paz e Terra, 1984.

LIMA, Antonio Carlos de Souza e VIANNA, Adriana de Resende Barreto. "História, Antropologia e relações de poder - algumas considerações em torno de saberes e fazeres sobre o social". In: MALERBA, Jurandir (org.). A velha História. Teoria, Método e Historiografia. SP, Papirus, 1996.

NORA, Pierre. Les lieux de Mémoire. Paris, Gallimard, 1984.

ORLANDI, Eni P. Análise do discurso. Campinas, Pontes, 1999.

PEEL, J. "Making history: the past in the Ijesha Presente". In: Man, 19, 1984.

POLLAK, Michael. "Memória e identidade social". In: Estudos Históricos, 5 (10). Rio de Janeiro, 1992.

. "Memória, Esquecimento, Silêncio. In: Estudos Históricos, 2 (3). Rio de Janeiro, 1989.

PROUST, Marcel. Em busca do tempo perdido. Vol. I. RJ; Ediouro, 1992.

SIMMEL, G. Conflit. The web of Group-Affiliations. London, Collier-MacMillan, 1955.

SOARES, A. (org.). Tempo e História. São Paulo, Companhia das Letras: Secretaria Municipal de Cultura, 1994.

THOMPSON, Paul. A Voz do Passado. História Oral. Rio de Janeiro, Paz e Terra, 1978.

VERNANT, Jean-Pierre. "Aspectos míticos da memória e do tempo". In: Mito e Pensamento entre os gregos. SP, Difel/Edusp, 1973.

WEBER, M. "Las comunidades políticas". In: Economia Y Sociedad. México, Fondo de Cultura Econômica, 1944.

\author{
Palavras-chave: \\ 1. novas tecnologias \\ 2. comunicação \\ 3. biografia \\ 4. escrita \\ 5. memória
}

